\title{
Biomass Type Selection for Boilers Using TOPSIS Multi-Criteria Model
}

\author{
S. Saelee, B. Paweewan, R. Tongpool, T. Witoon, J. Takada, and K. Manusboonpurmpool
}

\begin{abstract}
Biomass has been an important renewable alternative fuel for boilers in Thailand. In this paper, a multicriteria model in making complex decisions by Technique for Order Preference by Similarity to Ideal Solution (TOPSIS) was adopted as tool to select the preferred biomass from three typical biomass types (wood chips, palm shells and wood pellets). The multi-criteria are efficiency, price, ease to operate, Global Warming Potential (GWP) and Acidification Potential (AP). The boiler efficiency was measured by direct method in actual industrial boiler in Thailand. The prices were based on average Thailand market price as of January 2013. The ease to operate was obtained by factory operator interview. Global Warming Potentialand Acidification Potentialwere assessed by Life Cycle Assessment (LCA) method. The decision weighting values for efficiency, price, ease to operate, global warming potential and acidification potential were obtained by factory management interview at $30 \%, 30 \%, 10 \%, 20 \%$ and $10 \%$ respectively. TOPSIS selected wood chips as the most preferable biomass type followed by palm shells as second choice and wood pellets as third choice. The TOPSIS value equations to find preferred biomass type for different decision weighting values were then developed for general uses.
\end{abstract}

Index Terms-Biomass, boiler, efficiency, LCA, TOPSIS.

\section{INTRODUCTION}

The fossil fuel has been the primary energy resource, but the increase of fossil fuel prices together with environmental concerns drives to renewable and sustainable resources. "Biomass" is an alternative renewable fuel and also reduce Carbon dioxide $\left(\mathrm{CO}_{2}\right)$ emission according to carbon neutral rule [1]. Different Biomass types release pollutants differently depending on the chemical compositions and the energy content of each biomass type varies. Saiduret al. found rapeseed as a high-energy source at $27.8 \mathrm{MJ} / \mathrm{kg}$, while green wood had less energy content at $8 \mathrm{MJ} / \mathrm{kg}$ [1]. Wood pellet showed higher efficiency than wood residual by $22 \%$ but total annual operating cost of wood residual was less than wood pellet by $\$ 180 \mathrm{~K}[2]$. Asia has been growing in

Manuscript received August 15, 2013; revised October 5, 2013.

S. Saelee is with Advanced and Sustainable environmental engineering field, Kasetsart University, Bangkok, 10900, Thailand (e-mail: kkdasu@gmail.com).

B. Paweewan and T. Witoon are with Chemical Engineering Deaprtment, Kasetsart University, Bangkok, 10900 Thailand (e-mail: fengbtp@ku.ac.th, fengttwi@ku.ac.th).

R. Thongpool is with the National Science and Technology Development Agency, National Metal and Materials Technology Center (MTEC), Bangkok, 12120, Thailand (e-mail: rungnapt@mtec.or.th).

J. Takada is with the International Development Engineering Department, Tokyo Institute of Technology, Tokyo, 152-8550, Japan (email: takada@ide.titech.ac.jp).

K. Manusboonpurmpool was with Department of Chemical Engineering Kasetsart University, Bangkok, 10900, Thailand (e-mail: yoonanes@ hotmail.com). energy demand consistent to GDP growth.The energy development of Asia pacific scenario suggested that renewable usage ratio will increase about 1-2 times from years 2000 to years 2050. The economic benefits of wood and wood residual usage as fuel in boiler were different in different countries [3]. Hence, it is important for each country in the region to understand own country biomass and to select the right biomass type. Thailand used biomass fuel in boiler at $28 \%$ in industrial sector as mean to relieve the high fossil fuel prices in 1997 [4]. This study proposeda comprehensive decision making model usingmultiple criteria to select biomass type as combustion fuel in boiler.

TOPSIS is a decision-making technique. All criteria can be normalized into matrix pattern and calculated value with concept of distance from ideal and negative ideal solutions. The preferred choice is the one with nearest to ideal solution and farthest from negative ideal solution [5]. There are six steps in TOPSIS calculation. First step is to create decision matrix. Second step is to normalize the matrix by equation (1)

$$
r_{i j}=\frac{x_{i j}}{\sqrt{\sum_{j=1}^{n} x_{i j}^{2}}}
$$

When $m$ is alternative choices, $n$ is selected criteria, $x_{i j}$ is data before normalizing, $r_{i j}$ is data after normalizing $(i=1$, $2, \ldots ., m$ and $j=1,2, \ldots, n)$.

Third step is to obtain the weighted decision matrix by multiplying $r_{i j}$ with weighting values. Fourth step is to identify the positive ideal $\left(V_{j}^{*}\right)$ and negative ideal value $\left(V_{j}^{-}\right)$ of alternative choices in each criterion. Fifth step is to calculate the distance from positive ideal value $\left(S_{i}{ }^{*}\right)$ and negative ideal value $\left(S_{i}^{-}\right)$according to equation (2) and (3)

$$
\begin{gathered}
S_{i}{ }^{*}=\sqrt{\sum_{j=1}^{n}\left(V_{i j}-V_{j}{ }^{*}\right)^{2}} \\
S_{i}{ }^{-}=\sqrt{\sum_{j=1}^{n}\left(V_{i j}-V_{j}^{-}\right)^{2}}
\end{gathered}
$$

Last step is to calculate the relative closeness to ideal solutions or TOPSIS value $C_{i}{ }^{*}$ as shown in equation (4)

$$
C_{i}^{*}=\frac{S_{i}^{-}}{S_{i}{ }^{*}+S_{i}{ }^{-}}
$$

when $C_{i}^{*}$ is TOPSIS value.

The preferred choice is the one with highest TOPSIS value [6]

Boiler is a common boiled device that uses liquid as a medium to transfer heat at non-atmospheric pressure and receive heat from fuel combustion [7]. Efficiency is a key performance measurement in boiler. This study adopted 
direct efficiency method or Input-Output method, heat output divided by heat input. Heat input came from calorific value of fuel and fuel firing rate. Heat outputs were obtained by the measurements of enthalpy changes from feed water to steam. The direct efficiency is shown in equation (5)

$$
\begin{aligned}
& \text { Efficiency }(\%)= \\
& \frac{\text { steam flow rate } \times(\text { steam enthalpy }- \text { feed water enthalpy })}{\text { Fuel firing rate } \times \text { Gross calorific value }} \times 100
\end{aligned}
$$

The method to assess the environmental impacts in this study is Life Cycle Assessment (LCA), which is widely used and accepted method to assess environmental effect from each activity. The results depend on scope and boundary setting. LCA indicates the potential environmental impacts associated with products. It can be used to identify the main environmental problem in order to improve environmental performance of the product [8]. LCA is used as a tool for decision making. Moreover, eco-label and carbon trading are the applications of LCA. LCA study can be separated into four phases: 1) goal and scope definition, 2) inventory analysis, 3) impact assessment, and 4) interpretation phase.

\section{Methodology}

Three typicalbiomass types were selected from the market Thailand [4]. First one was wood chips coming from wood cutting businesses.Second one was palm shells, waste from palm oil production in Thailand as the thirdlargest palm production country in the world [9]. The third one was wood pellets, compressed biomass from wood dust. Wood pellets were having good energy efficiency, easy to store and transport, and low humidity [10].

\section{A. Technique for Order Preference by Similarity to an Ideal Solution (TOPSIS) Methodology}

The criteria were created with agreement from factory management team in Thailand. Tangible criteria were efficiency, fuel price, global warming potential (GWP) and acidification potential (AP). Non-tangible criterion was ease to operate. The non-tangible criterion was obtained by operators' interview and then quantified into 1 to 5 scales. The selected environmental related impacts, global warming and acidification, were consistent to studies in Europe [11], [12]. Fuel prices were based on average commercial market prices as of January 2013 in Thailand.

\section{B. Boiler Efficiency}

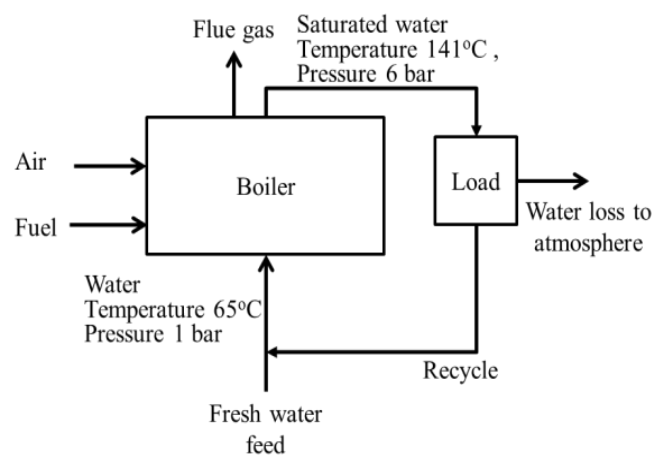

Fig. 1. The schematic of boiler system.
The boiler investigated in this study was fire tube type with steam production power 120 Brake Horse Power (BHP) and maximum operating pressure 10 bars. Boiler efficiency was measured under actual operating condition, consistent to Industrial standard and British standard (IS 8753 and BS845) [13]. The efficiency was calculated by direct method as equation (5). The measurements were done under steady state operation and all readings were taken at an hour after steady state was reached. The simplified diagram of boiler was as shown in Fig. 1.

\section{Biomassproperties}

Moisture: This moisture content was measured by the weight differences between initial sample at room temperature and sample after heating at $105^{\circ} \mathrm{C}$ for 17 hours as shown in equation (6) [14].

$$
\begin{aligned}
& \% \text { Moisture content }= \\
& \frac{(\text { The weight of water in sample })}{\text { Total innitial weight of sample }} \times 100
\end{aligned}
$$

Gross calorific value (GCV):The actual energy from each biomass type was measured by Bomb Calorific meter model PARR 1261 at Kasetsart University, the standard instrument for measuring gross calorific values of solid and liquid fuel samples [15].

\section{Life Cycle Assessment (LCA)}

The environmental burden of energy produced from boiler was evaluated using CML 2000 assessment method [16] via SimaPro software (Version 7.3.3). The impact categories of GWPand AP were focused.

Goal and Scope: The aim of this assessment was to evaluate and compare environmental impacts of the energy from three types of biomass; wood chips, palm shells and wood pellets, in boiler operation.

Functional Unit: The output product was the energy of 1 MJ steam.

System boundary: The data included the transportation of biomass from the original sources to the operating factory, the production of electricity and water as well as the air emissions from combustion process. The data of wood pellets production were also included. Carbon dioxide $\left(\mathrm{CO}_{2}\right)$ emission from combustion process was excluded according to carbon neutral rule. The boiler maintenance was excluded as the same maintenance was applied for the boiler using these three biomass types.

Inventory data and assumptions: Electricity was used for pumps and motors. The air emissions were calculated using emission factor of combustion process from Asian emission factor in industrial boiler [3]. The LCI of transportation, electricity and water were obtained from Thai national LCI database [17].

\section{RESULTS AND DisCUSSIONS}

\section{A. Boiler Operation Result}

The measuring results of boiler were shown in Table I, water temperatures were used to valuate enthalpy using standard steam table and each value was then used for 
efficiency calculation by equation (5).

Fuel properties, input material and boiler efficiency were shown in Table II.

Among the three biomass types, palm shells type showed highest efficiency at $58 \%$ while wood chips type had least efficiency at $45 \%$. GCV of wood chips was higher than of wood pellets but the efficiency of wood chips was lower than wood pellets, consistent to the study of Envirochem Services Inc. [18] that the lower moisture content biomass could becombusted better than higher moisture content biomass.

\section{B. LCA Result}

The assessments environmental impacts were shown in Fig. 2(a) and (b). The GWP of the energy from wood chips, palm shells and wood pellets were $6.26 \times 10^{-3}, 6.29 \times 10^{-3}$, and $24.99 \times 10^{-3} \mathrm{~kg} \mathrm{CO}_{2}$ equivalent per $\mathrm{MJ}$, respectively. The AP of the energy from wood chips, palm shells and wood pellets were $3.61 \times 10^{-5}, 3.52 \times 10^{-5}$, and $12.67 \times 10^{-5} \mathrm{~kg}$ $\mathrm{SO}_{2}$ equivalent per $\mathrm{MJ}$, respectively. The major contributors for wood chips and palm shells were the combustion and transportation stages while that for wood pelletswas the production of the pellet production process.

TABLE I: BOILER EXPERIMENTAL RESULT

\begin{tabular}{|c|c|c|c|}
\hline Type & Wood Chips & Palm Shells & Wood Pellet \\
\hline Fuel firing rate $(\mathrm{kg} / \mathrm{h})$ & 231 & 161 & 203 \\
\hline Fresh water feed to Boiler $(\mathrm{kg} / \mathrm{h})$ & 5,492 & 5,210 & 5,284 \\
\hline Water temperature to feed to boiler at $1 \mathrm{bar}\left({ }^{\circ} \mathrm{C}\right)$ & 61 & 64 & 64 \\
\hline Enthalpy of water to feed to boiler $(\mathrm{kJ} / \mathrm{kg})$ & 255 & 268 & 268 \\
\hline Saturated water at 6 bar $\left({ }^{\circ} \mathrm{C}\right)$ & 141 & 141 & 141 \\
\hline Enthalpyof saturated water (kJ/kg) & 593 & 593 & 593 \\
\hline
\end{tabular}

TABLE II: FUEL PROPERTIES AND EFFICIENCY

\begin{tabular}{lccccc}
\hline \hline \multirow{2}{*}{ Fuel type } & \multicolumn{2}{c}{ Fuel Properties } & Heat input & $\begin{array}{c}\text { Heat Output } \\
(\mathrm{MJ} / \mathrm{day})\end{array}$ & $\begin{array}{c}\text { Efficiency } \\
(\%)\end{array}$ \\
\cline { 2 - 5 } & $\mathrm{GCV}(\mathrm{kJ} / \mathrm{kg})$ & $\begin{array}{c}\text { Moisture content } \\
(\%)\end{array}$ & 10.46 & 36,896 & 16,714 \\
Wood Chips & 17,785 & 10.04 & 26,516 & 15,269 & 45 \\
Palm shells & 18,311 & 5.36 & 31,796 & 15,485 & 49 \\
Wood pellets & 17,404 & & & & 58 \\
\hline \hline
\end{tabular}

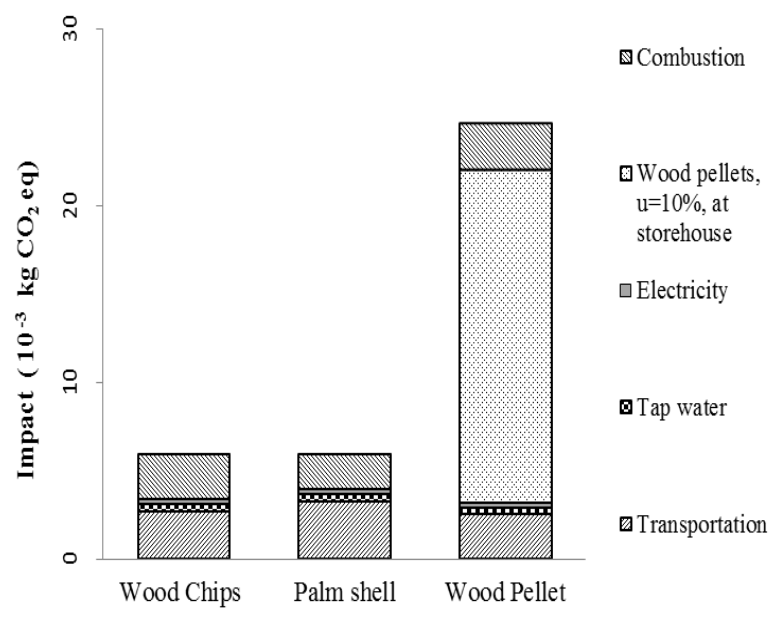

(a)

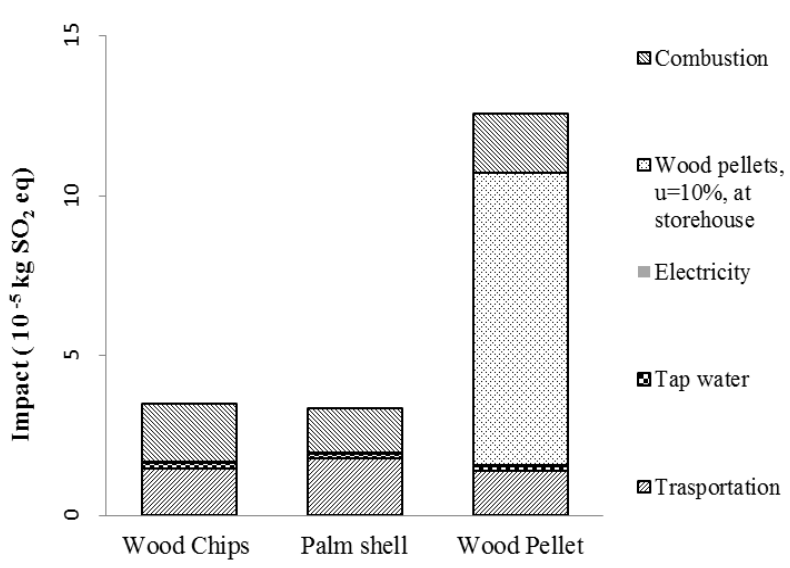

(b)

Fig. 2. The Environmental impacts assessment for the production of the steam of $1 \mathrm{MJ}$ generated by Wood chips, Palm shells and Wood pellets (a) GWP, (b) AP.

Among the three biomass types, the wood chips provided less impactin the GWP and palm shells showed less AP. The GWP and AP of wood chips and palm shellswere almost the same. Although palm shells hadhigher efficiency than wood chips, the requirementfor transport and electricity for palm shellsmade wood chips to be the environmentalfriendly type.

The environmental impacts of wood pellets were the highest, or about 4 times higher than the others two due to additional pelleting process requirements.

\section{Decision Making Using TOPSIS}

TABLE III: INVESTIGATION RESULT

\begin{tabular}{|c|c|c|c|}
\hline Item & Wood chips & Palm shells & Wood pellets \\
\hline Price $(* \$ /$ ton $)$ & 23 & 100 & 117 \\
\hline Ease to operate & Difficult(3) & Easy(1) & Easy(1) \\
\hline
\end{tabular}

*Exchange rate; 30 Thai Baht $=1 \$$

Boiler efficiency results (Table II), LCA results (Fig. 1), 
price and ease to operate (Table III), were used to develop decision making matrixusing TOPSIS method. The intangible criterion (ease to operate factor) was transformed into tangible number by 1-5 scale as shown in Table III.

$$
\begin{gathered}
C_{1}=\frac{\sqrt{0.497 x_{2}^{2}+0.441 x_{3}^{2}+0.361 x_{4}^{2}}}{\sqrt{0.497 x_{2}^{2}+0.441 x_{3}^{2}+0.361 x_{4}^{2}}+\sqrt{0.02 x_{1}^{2}+0.363 x_{5}^{2}}} \\
C_{2}=\frac{\sqrt{0.02 x_{1}^{2}+0.496 x_{2}^{2}+0.451 x_{3}^{2}+0.011 x_{4}^{2}+0.364 x_{5}^{2}}}{\sqrt{0.02 x_{1}^{2}+0.496 x_{2}^{2}+0.451 x_{3}^{2}+0.011 x_{4}^{2}+0.364 x_{5}^{2}}+\sqrt{0.243 x_{4}^{2}}} \\
C_{3}=\frac{\sqrt{0.001 x_{1}^{2}+0.364 x_{5}^{2}}}{\sqrt{0.001 x_{1}^{2}+0.364 x_{5}^{2}}+\sqrt{0.01 x_{1}^{2}+0.497 x_{2}^{2}+0.451 x_{3}^{2}+0.361 x_{4}^{2}}}
\end{gathered}
$$

$C_{1}, C_{2}$ and $C_{3}$ were TOPSIS value of wood chips, palm shells and wood pellets respectively.

$x_{1}, x_{2}, x_{3}, x_{4}$ and $x_{5}$ were weighting values of efficiency, GWP, AP , fuel price and ease to operate respectively.

The higher value is chosen as preferred alternative.

TOPSIS multi-criteria model is flexible to be adopted for actual industry biomass selection by its capability to handle both tangible and intangible multiple criteria.

The weighting valuesby factory management interview were $30 \%$ for fuel efficiency, $20 \%$ forGWP, $10 \%$ for AP, $30 \%$ for fuel price and $10 \%$ for ease to operate. The TOPSIS values were $0.76,0.54$ and 0.20 of wood chips, palm shells and wood pelletsrespectively. This suggested wood chips as the preferred biomass type for this factory. TOPSIS maintained the same result to select wood chips when the efficiency was adjusted from actual factory data into typical $70 \%$ efficiency for all biomass types [19] as shown in Table IV.This confirmed wood chips as the preferable biomass for this company.

The sensitivity analyses were done by varying the weighting values of one main criterion as shown in Fig. 3, weighting values of other criteria were based on average proportion from factory interview data. The result showed that wood chips type was not the preferred choice when weighting value for efficiency, acidification, and easy to operate were greater than $60 \%, 100 \%$ and $30 \%$ respectively or,weighting value of fuel price lower than $20 \%$.TOPSIS also suggested wood pellets, as none-preferred biomass type

\begin{tabular}{|c|c|c|c|c|c|c|c|}
\hline & \multirow{3}{*}{ Item } & \multicolumn{6}{|c|}{ Weighting value $(\%)$} \\
\hline & & 30 & 20 & 10 & 20 & 10 & \\
\hline & & $\begin{array}{c}\text { Efficiency } \\
(\%)\end{array}$ & $\begin{array}{c}\text { GWP } \\
\text { ( } \mathrm{CO}_{2} \text { Equivalent) }\end{array}$ & $\begin{array}{c}\mathrm{AP} \\
\left(\mathrm{SO}_{2} \text { Equivalent }\right)\end{array}$ & Price(US\$/Ton) & $\begin{array}{l}\text { Ease to } \\
\text { operate }\end{array}$ & $\begin{array}{l}\text { TOPSIS } \\
\text { value }\end{array}$ \\
\hline \multirow{3}{*}{$\begin{array}{l}\text { Actual } \\
\text { investigated } \\
\text { efficiency }\end{array}$} & Wood Chips & 45 & $6.26 \mathrm{E}-03$ & $3.61 \mathrm{E}-05$ & 23 & 3 & 0.76 \\
\hline & Palm shell & 58 & $6.29 \mathrm{E}-03$ & $3.52 \mathrm{E}-05$ & 100 & 1 & 0.54 \\
\hline & Wood pellet & 49 & $2.49 \mathrm{E}-02$ & $1.27 \mathrm{E}-04$ & 117 & 1 & 0.20 \\
\hline \multirow{3}{*}{$\begin{array}{l}\text { Typical } \\
\text { efficiency } \\
{[19]}\end{array}$} & Wood Chips & 70 & $4.22 \mathrm{E}-03$ & $2.38 \mathrm{E}-05$ & 23 & 3 & 0.80 \\
\hline & Palm shell & 70 & $5.24 \mathrm{E}-03$ & 2.91E-05 & 100 & 1 & 0.52 \\
\hline & Wood pellet & 70 & $1.74 \mathrm{E}-02$ & $8.85 \mathrm{E}-05$ & 117 & 1 & 0.20 \\
\hline
\end{tabular}
in most cases as show in Fig. 3.

TABLE IV: TOPSIS RESULT OF ACTUAL AND THEORY EFFICIENCY OF BOILER

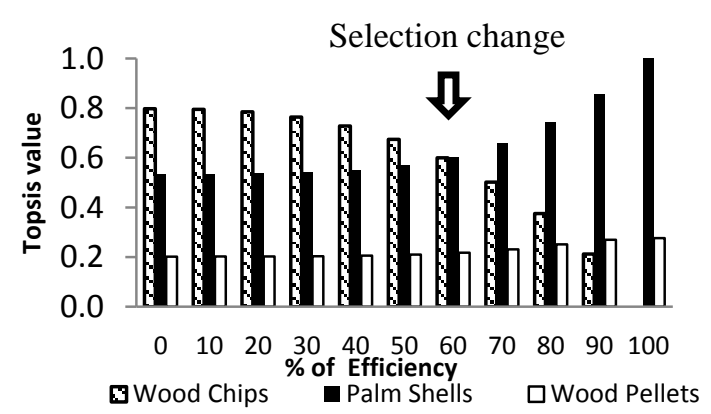

(a)

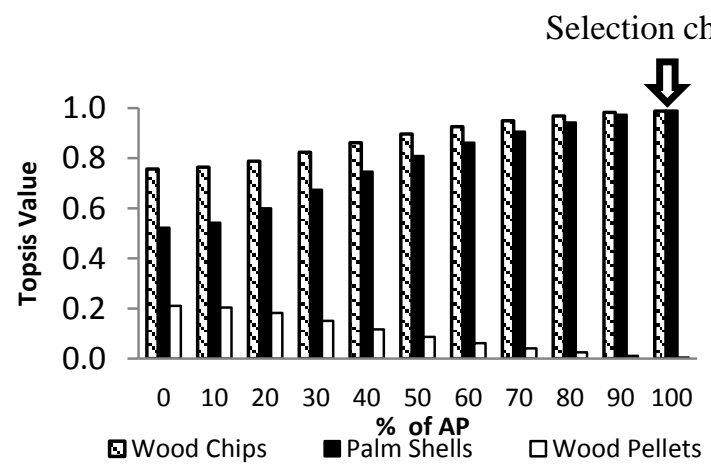

(c)

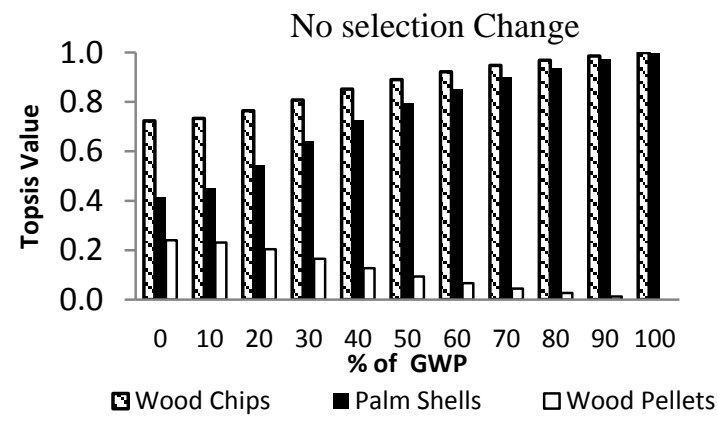

(b)

Selection change

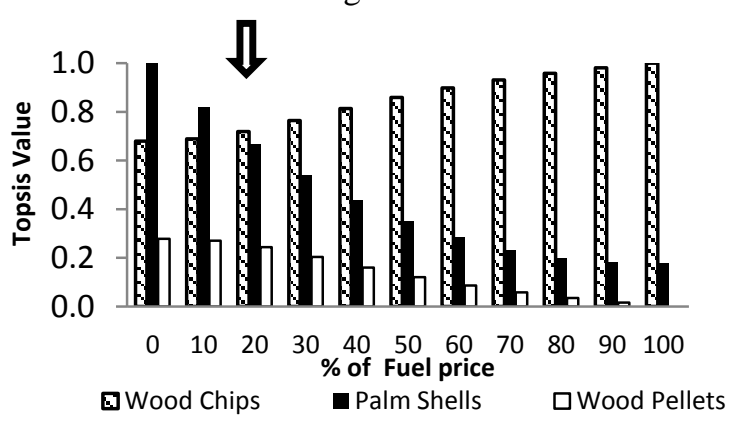

(b) 
Selection change

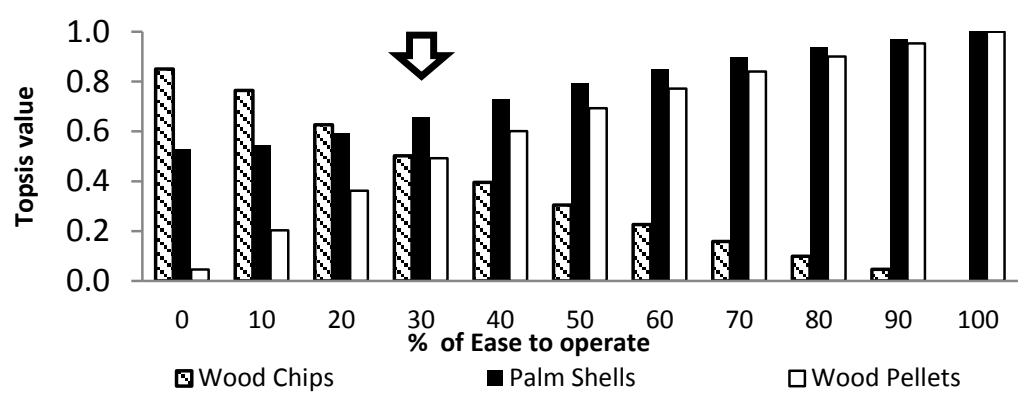

(e)

Fig. 3. The result of sensitivity analysis by varying weighting values.

\section{CONCLUSION}

TOPSIS together with LCA and thermodynamic data was successfully adopted as powerful tool to select the preferred biomasstype usingmulti-criteria of efficiency, price, and ease to operate, GWP, and AP. TOPSIS mathematical models for biomass type selection were developed for this investigated company and also for general uses by differing weighting value. Wood chips is generally the most preferred biomass type for this company while the palm shells is in second place and wood pellets as the last choice.

\section{ACKNOWLEDGEMENT}

Thank should go toKasetsart UniversityResearch and Development Institute, (KURDI)), National Metal and Material Technology Center (MTEC) and Tokyo Institute of Technology (Tokyo Tech).

\section{REFERENCES}

[1] R. Saidur, E. A. Abdelaziza, A. Demirbas, M. S. Hossain, and S. Mekhilef, "A review on biomass as a fuel for boilers," Renewable and Sustainable Energy Reviews, vol. 15, pp. 2262-2289, 2011.

[2] J. Chau, T. Sowlati, S. Sokhansanj, F. Preto, S. Melin, and X. Bi, "Techno-economic analysis of wood biomass boilers for the greenhouse industry,"Applied Energy, vol. 86, pp. 364-371, 2009.

[3] S. C. Bhattacharya, R. A. Attalage, M. A. Leon, G. Q. Amur, P. A. Salam, and C. Thanawat, "Potential of biomass fuel conservationin selected Asian countries," Energy Conversion and Management, vol. 40, pp.1141-1162, 2000.

[4] The National Energy Policy Office, "Thailand biomass based power generation and cogeneration within small rural industries," Nov. 2000.

[5] T. Y. Chen and C. Y. Tsa, "The interval-valued fuzzy TOPSIS method and experimental analysis, Fuzzy Sets and Systems," Fuzzy Sets and Systems, vol. 159, pp. 1410-1428, 2008.

[6] E. Manokaran, S. Subhashini, S. Senthilvel, R. Muruganandham, and K. Ravichandran, "Application of multi criteria decision making tools and validation with optimization technique-case study using TOPSIS, ANN \& SAW," International Journal of Management \& Business studies, vol. 1, pp. 112-113, 2011.

[7] Department of Industrial Work, "The safety testing method of boiler or heated device which use liquid as a medium to transfer heat at nonatmospheric pressure," Department Notification, vol. 123, pp. 1-2, 2006.

[8] Environmental management Life cycle assessment Requirements and guidelines, ISO Standard, ISO 14044: 2006.

[9] E. Saxon and S. Roquemore, "The root of the problem," Union of concerned scienceisis, ch. 6, June 2011.

[10] V. Karkania, E. Fanara, and A.Zabaniotou, "Review of sustainable biomass pellets production; A study for agricultural residues pellets' market in Greece," Renewable and Sustainable Energy Reviews, pp. 1426-1436, Jan. 2012.
[11] P. A. Beauchemin and M. Tampier, "Emissions from wood-fired combustion equipment," Envirochem Services Inc., Final report, pp. 5, June 2008.

[12] Continuing Education and Development Inc.. Boiler fuels, emissions and efficiency. [Online]. Available: http://www.cedengineering.com

[13] Bureau of Energy Efficiency. Energy performance assessment of boilers. [Online]. pp. 1-5. Available: http://www.em-ea.org

[14] Biomass Energy Centre. (2011) Testing Moisture Content. [Online]. 1. Available: http://www.biomassenergycentre.org.uk

[15] Ramkamhang University. The method to find accumulates energy in food product by bomb calorimeter. [Online]. Available: http://www.ebook.ram.edu/e-book

[16] R. Frischknecht, "The ecoinvent database," Int. J. Life Cycle Assess, pp. 1-94, 2005.

[17] Thai LCA National Database, National Metal and Materials Technology Center (MTEC), 2012.

[18] The New York State Energy Research and Development Authority, "Biomass combustion in Europe; overview on technologies and regulations," 2008.

[19] Council of Industrial Boiler Owners. (Sep. 2012). Energy efficiency and industrial boiler efficiency; an industry perspective. [Online]. Available: http://www.cibo.org/pubs/whitepaper1.pdf

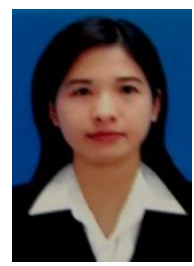

S. Saelee was born in Thailand. She did her first degree in Chemical Engineering, King Mongkut's University of Technology Thonburi, Bangkok, Thailand.

Ms. SudaratSaelee worked with Honda R\&D Asia pacific until 2012 and was responsible to project development and research for South East Asia, South Asia and Australia areas. She is now undertaking master degree under a collaboration program between Japan (Tokyo Institute of Technology) and Thailand (Kasetsart University, and National Science and Technology Development Agency).

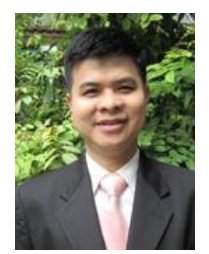

B. Paweewan was born in Thailand. He did his first degree in Chemical Engineering, Kasetsart University, Bangkok, Thailand, and Ph.D. degree from University of Cambridge, United Kingdom.

Dr. Boontham Paweewan had worked with Esso (Thailand) Public Company and ExxonMobil Asia Pacific (Singapore) until 2010. He is currently a director at Cambridge Thai Foundation and a LECTURER at Department of Chemical Engineering, Kasetsart University, Thailand.

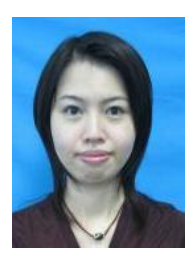

R. Tongpool was born in Thailand. She did her first degree in Chemistry, Kasetsart University, Bangkok, Thailand, and Ph.D. degree in Ceramic Materials, University of Manchester Institute of Science and Technology, United Kingdom.

Dr. Rungnapa Tongpool is currently a researcher at Life Cycle Assessment Lab, National Metal and Materials Technology Center, Thailand. Her research interests are life cycle assessment and eco-product development. Her publications are Kinetics of nitrogen dioxide exposure in lead phthalocyaninesensors, Analysis of steel production in Thailand: Environmental impacts and solutions and Improvement of the environmental performance of broiler feeds: a study via life cycle assessment. 


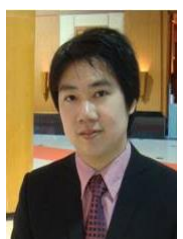

T. Witoon was born in Thailand. He received the Scholarship from the Royal Golden Jubilee (RGJ) Program under the Thailand Research Fund (TRF) for doctoral degree study in Kasetsart University, Thailand.

Dr. ThongthaiWitoon is currently a lecturer at Department of Chemical Engineering, Kasetsart University, Thailand. His research focuses are mainly on the synthesis of nanomaterial, $\mathrm{CO}_{2}$ separation from hot gas, and fine chemical production from $\mathrm{CO}_{2}$ hydrogenation reaction. His works have been appeared in international journals including Materials Letters, Materials Chemistry and Physics, Colloids and Surfaces A Physicochemical and Engineering Aspects, Fuel Processing Technology and Ceramics International.

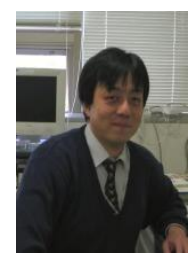

J. Takada was born in Japan. He did his D. Eng. degree from Tokyo Institute of Technology, Japan.

Dr. Jun-ichi Takada is currently a professor at International Development Engineering department, Tokyo Institute of Technology and a visiting researcher of medial ICT Group, National Institute of Information and Communications Technology, Japan.

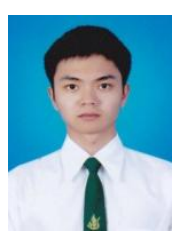

K. Manusboonpurmpool was born in Thailand. $\mathrm{Mr}$ Kanin Manusboonpurmpool did his first degree in Chemical Engineering, Kasetsart University, Bangkok, Thailand in 2013. 